\title{
A 3,000-year-old child's toy
}

\author{
Ioannis N. Mammas • Demetrios A. Spandidos
}

Received: 16 June 2012 / Accepted: 26 June 2012 /Published online: 13 July 2012

(C) Springer-Verlag 2012

\begin{abstract}
We present the oldest children's toy in Europe, the clay horse of Lefkandi (tenth to ninth century BC), which was found on the western coast of the island of Euboea in Greece. This remarkable 3,000-year-old toy, carrying not a warrior but a pair of amphoras, does not promote violence and it rather enhances creativity, coordination, and an understanding of the mechanics of wheeled vehicles.
\end{abstract}

\section{Keywords Toy $\cdot$ Child $\cdot$ History}

Amidst the vases and jewelry of the Archaeological Museum of Eretria, located in the ancient town (polis) of Eretria on the western coast of the island of Euboea in Greece, there is the oldest children's toy that has been found in Europe, the clay horse of Lefkandi. This remarkable clay horse (see Fig. 1) was discovered in the nearby village of Lefkandi in the grave of a boy who lived and died in the island of Euboea between the tenth and ninth century BC [2]. It was made in the region of Attica, across the South Evian Sea, and was brought back as a present from a voyage by his parent.

As toys offered by parents provide children with a message about what is valued [1], the parental choice to obtain a horse which carried not a warrior but a pair of amphoras is really outstanding. Obviously, this toy does not promote violence. It rather enhances creativity by helping the child to develop motor skills, coordination,

I. N. Mammas $(\bowtie)$

First Pediatric Department, 'Penteli' Children's Hospital,

Athens, Greece

e-mail: mammasjo@googlemail.com

D. A. Spandidos

Department of Clinical Virology,

University of Crete School of Medicine,

Heraklion, Greece

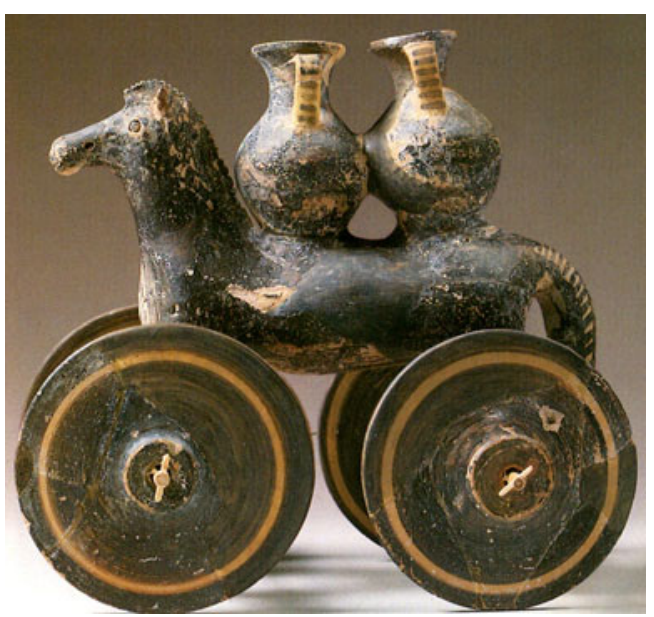

Fig. 1 The clay horse of Lefkandi, island of Euboea, Greece: a 3,000year-old child's toy (tenth to ninth century BC)

and perhaps an understanding of the mechanics of wheeled vehicles.

One suspects that, just as contemporary children visiting the museum instantly recognize this 3,000-year-old toy as a familiar item, the concerns and motivations of parents in the ancient world may not have been too dissimilar from those of parents today.

Conflict of interest None is declared.

\section{References}

1. Glassy D, Romano J, American Academy of Pediatrics, Committee on Early Childhood, Adoption and Dependent Care (2003) Selecting appropriate toys for young children: the pediatrician's role. Pediatrics 111:911-913

2. Sakellaraki E (2000) Eretria site and museum. Ministry of Culture Archaeological Receipts Fund, Athens 